\title{
BMJ Open Effect of different ranges of systolic blood pressure on left ventricular structure and diastolic function in a Chinese population: a cross-sectional population-based Shunyi study
}

Liu Yongtai, ${ }^{\oplus}$ Lai Jinzhi, ${ }^{1}$ Zhou Lixin, ${ }^{2}$ Zhai Feifei, ${ }^{2}$ Zhang Dingding, ${ }^{3}$ Tian Zhuang, ${ }^{1}$ Zhu Yanlin, ${ }^{1}$ Chen Wei, ${ }^{1}$ Bai Hua, ${ }^{\oplus}$ Wang Hui, ${ }^{1}$ Zhu Yicheng, ${ }^{2}$ Cui Liying, ${ }^{2}$ Jin Zhengyu, ${ }^{4}$ Shuyang Zhang ${ }^{1}$

To cite: Yongtai L, Jinzhi L, Lixin Z, et al. Effect of different ranges of systolic blood pressure on left ventricular structure and diastolic function in a Chinese population: a cross-sectional populationbased Shunyi study. BMJ Open 2019;9:e028398. doi:10.1136/ bmjopen-2018-028398

- Prepublication history for this paper is available online. To view these files, please visit the journal online (http://dx.doi. org/10.1136/bmjopen-2018028398).

LY and LJ contributed equally.

Received 23 December 2018

Revised 11 July 2019

Accepted 12 July 2019
Check for updates

(C) Author(s) (or their employer(s)) 2019. Re-use permitted under CC BY-NC. No commercial re-use. See rights and permissions. Published by BMJ.

For numbered affiliations see end of article.

Correspondence to Professor Shuyang Zhang; shuyangzhang103@163.com

\section{ABSTRACT}

Objectives To evaluate the effect of different ranges of systolic blood pressure (SBP) on left ventricular (LV) geometry and diastolic function in Chinese population. Design Cross-sectional study.

Setting Peking Union Medical College Hospital in Beijing, China.

Participants All inhabitants aged 35 years or older, living in five villages of Shunyi were invited. Exclusion criteria included individuals who declined participation, presence of moderate to severe valvular heart disease, persistent atrial fibrillation and suboptimal echocardiograms.

Interventions The baseline data of 1051 participants were analysed. The relationship between SBP and LV geometric and diastolic function assessed by echocardiography was analysed after adjusting for conventional cardiac risk factors.

Results The adjusted value of SBP was independently associated with LV hypertrophy (LVH) and LV diastolic dysfunction (LVDDF) (all $p<0.01)$. Setting individuals with SBP $<120 \mathrm{~mm} \mathrm{Hg}$ as the reference group (group 1), those with SBP between $120 \mathrm{~mm} \mathrm{Hg}$ and $140 \mathrm{~mm} \mathrm{Hg}$ (group 2) had higher risk odds of LVH and those with SBP $\geq 140 \mathrm{~mm}$ $\mathrm{Hg}$ (group 3) had higher risk odds of LVH and LVDDF (all $\mathrm{p}<0.01$ ). With the increase of SBP, LV mass index (LVMI) and $E / e^{\prime}$ stepwise increased and $e^{\prime}$ stepwise decreased significantly from group 1 to 3 (all $p<0.05$ ). In the whole population, SBP was independently correlated with LVMI, LVEDD, Left Atrial Volume Index, $\mathrm{e}^{\prime}$, and $\mathrm{E} / \mathrm{e}^{\prime}$ (all $\mathrm{p}<0.01$ ). Conclusions SBP was independently related to LVH and LVDDF, SBP between 120 and $140 \mathrm{~mm} \mathrm{Hg}$ was independently related to worse LV remodelling and diastolic function, these findings indicated the potential benefit of intensive SBP control.

\section{INTRODUCTION}

It is well known that hypertension is a very important risk factor for cardiovascular disease. $^{1-4}$ According to 2018 European Society of Cardiology guideline, hypertension was defined as office systolic blood pressure
Strengths and limitations of this study

- The strengths of the study include its large sample from the general Chinese population and its standardised acquisition of basic characteristics and echocardiography examinations.

- A limitation is that this is a cross-sectional study and cannot prove a causal relationship between the geometric/functional changes and systolic blood pressure.

- Another limitation is that this study was conducted in a Chinese population; studies that involve other ethnic populations are needed to replicate our results.

(SBP) values at least $140 \mathrm{~mm} \mathrm{Hg}$ and/or diastolic BP (DBP) values at least $90 \mathrm{~mm} \mathrm{Hg.}{ }^{5}$ A complex series of changes in the geometry and function occur in the hearts of patients with hypertension. ${ }^{6}$ In these patients, the alterations in left ventricular (LV) geometry, delayed myocardial relaxation, increased passive stiffness of the sarcomere and extracellular matrix, and altered myocardial tone will cause LV remodelling and influence diastolic function. ${ }^{7}$ In the latest study, impairment of LV geometry and diastolic function was observed even in prehypertensive patients, ${ }^{8-10}$ who were defined as having a SBP ranging from 120 to $139 \mathrm{~mm} \mathrm{Hg}$ and/or DBP from 80 to $89 \mathrm{~mm} \mathrm{Hg}$.

Elevations in SBP, particularly among older adults, are usually the result of stiffness in the large arteries and SBP appears to be a better predictor of events than DBP. ${ }^{11}{ }^{12}$ Increasing emphasis has been placed on SBP alone as the most useful predictor of cardiovascular disease in hypertensive individuals and several guidelines have supported the use of 
1,586 individuals were invited 461 individuals refused echocardiography examination.

1,125 individuals

59 individuals with incomplete clinical data

1,066 individuals \begin{tabular}{|l}
6 individuals with moderate to sever valvular disease, and \\
4 individuals with persistent atrial fibrillation.
\end{tabular}

1,056 individuals

$\longrightarrow 5$ individuals with poor echocardiography image quality

1,051 individuals were included in the analysis

Figure 1 The participants' flow chart with respect to inclusion and exclusion. A total of 1586 inhabitants aged 35 years or older were invited. Exclusion criteria included individuals who declined participation, presence of moderate to severe valvular heart disease, persistent atrial fibrillation and suboptimal echocardiograms. Finally, 1051 individuals were included in this study.

SBP and strongly encourage the use of SBP goals in antihypertensive treatment. ${ }^{10}$

In the newest Chinese guideline, ${ }^{13}$ the 'high normal' SBP was defined as SBP between 120 and $140 \mathrm{~mm} \mathrm{Hg}$. Our hypothesis is that SBP between 120 and $140 \mathrm{~mm} \mathrm{Hg}$, regardless of the DBP level, increases the risk odds of $\mathrm{LV}$ remodelling and LV diastolic dysfunction (LVDDF) in Chinese adults.

The present study was a part of the ongoing community-based Shunyi study in China, designed to investigate the risk factors for cardiovascular and age-related diseases. In this study, we analysed the effect of different ranges of SBP on LV remodelling and diastolic function in the Chinese population.

\section{METHODS}

\section{Population}

All inhabitants aged 35 years or older, living in five villages of Shunyi, a suburb district of Beijing, were invited, and the demographic data were recorded from June 2013 to April 2016. Exclusion criteria included individuals who declined participation, presence of moderate to severe valvular heart disease, persistent atrial fibrillation and suboptimal echocardiograms. Finally, 1586 individuals participated and standard baseline assessments were undertaken. All participants were invited for echocardiographic examination. Among those, 461 participants refused. Thus, the baseline echocardiography was performed in $1125(70.9 \%)$ participants. The individuals with incomplete clinical data (59 individuals), moderate to severe valvular disease (6 individuals), persistent atrial fibrillation ( 4 individuals), and poor image quality ( 5 individuals) were excluded. The final analysis was performed based on 1051 subjects (figure 1).

\section{Patient and public involvement}

Neither patients nor public were involved in the development of the research question, study design, outcome measures, recruitment to and conduct of the study. The results of the study will be disseminated to participants through lectures presented by the investigators.

\section{Assessment of the conventional risk factors affecting LV geometry and function}

Conventional cardiovascular risk factors affecting LV geometry and function were selected and included in the analysis based on medical knowledge and previous reports included age, gender, heart rate (HR), body mass index (BMI), physical activity, smoking and alcohol drinking status, SBP, antihypertensive treatment, blood glucose level, serum low-density lipoprotein cholesterol (LDL-C) level, history of coronary heart disease (CHD) and renal function.

BMI was calculated by the weight in kilograms indexed to the height in metres squared. Smoking status was classified as current smoking (at least within the past 1 month) and non-current smoking. Alcohol drinking status was classified into current alcohol drinking (at least once per week within the past 1 month) and non-current alcohol drinking. We also collected the self-report degree of individual physical activity including five grades: very light, light, moderate, heavy and very heavy physical activity.

$\mathrm{BP}$ was measured by trained nurses and physicians on sitting position, supporting the limb used to measure BP, ensuring the BP cuff was at heart level, using a validated oscillometric device (Omron HEM-7211) three times after a 5 min rest and the mean value was used. Each BP measurement took place in at least $30 \mathrm{~s}$ interval, having the patient sit quietly for $5 \mathrm{~min}$ before a reading is taken. Hypertension was defined as self-reported hypertension, antihypertensive treatment, SBP $\geq 140 \mathrm{~mm} \mathrm{Hg}$ or DBP $\geq 90 \mathrm{~mm} \mathrm{Hg}$. The device used in the biochemical test was Beckman AU 5800. Venous blood samples, routinely drawn after an overnight fast, were analysed for glycated haemoglobin A1c (HbA1c), plasma LDL-C and plasma glucose levels. Because of the large fluctuations in fasting blood glucose, HbA1c was chosen as an indicator of the blood glucose level. History of CHD was confirmed by two independent experienced cardiologists according to the patient's medical history, symptoms, electrocardiography and other imaging data. If there was disagreement about the final diagnosis, a third cardiologist refereed. Renal function was expressed as estimated glomerular filtration rate (eGFR), which was calculated using the Chronic Kidney Disease Epidemiology Collaboration $\left(\right.$ CKD-EPI) equation, eGFR $=141 \times \min (\mathrm{Scr} / \kappa, 1)^{\alpha} \times \max$ $(\mathrm{Scr} / \kappa, 1)^{-1.209} \times 0.993^{\text {Age }} \times 1.018$ (if female), where Scr is serum creatinine, $\kappa$ is 0.7 for females and 0.9 for males, $\alpha$ is -0.329 for females and -0.411 for males, min indicates the minimum of Scr/ $/$ or 1 , and max indicates the maximum of $\mathrm{Scr} / \kappa$ or 1 . 


\section{Echocardiography}

Echocardiography was performed using commercially available equipment (Vivid I; GE Vingmed Ultrasound, Horten, Norway). All studies were performed and reviewed by cardiologists with advanced training in echocardiography.

Left atrial anteroposterior dimension (LAD), LV end-diastolic dimension (LVEDD), interventricular septal wall thickness (IVST), LV posterior wall thickness (LVPWT), LV end-diastolic volume (LVEDV), LV end-systolic volume (LVESV), LV ejection fraction(), LV mass (LVM) and Left Atrial Volume Index (LAVI) were assessed according to the Guideline of the American Society of Echocardiography. ${ }^{14}$ LAD, LVEDD, IVST and LVPWT were measured in the parasternal long-axis view using M-mode echocardiography. Relative wall thickness (RWT) was calculated with the following formula: $2 \times$ LVPWT/LVEDD. LA volume was measured in a biplane calculation from both the apical four and two-chamber views, and LAVI was calculated by LA volume indexed to body surface area (BSA). LVM was calculated by linear dimension technique, and LVM index (LVMI) was the result of LVM indexed to BSA. LVEDV, LVESV and LVEF were assessed using the modified biplane Simpson's equation in the apical four and two-chamber views.

Mitral inflow was assessed with pulsed-wave Doppler echocardiography from the apical four-chamber view. ${ }^{15}$ The Doppler beam was aligned parallel to the direction of flow, and a 1-2 $\mathrm{mm}$ sample volume was placed between the tips of mitral leaflets during diastole. From the mitral inflow profile, the E-wave (E) and A-wave (A) velocity and $\mathrm{E} / \mathrm{A}$ ratio were measured.

Tissue Doppler imaging (TDI) was performed at the apical four-chamber view for the long-axis motion of the heart. ${ }^{15} 16$ Two-dimensional echocardiography with colour TDI was performed. The imaging angle was adjusted to ensure a parallel alignment of the sampling window with the myocardial segment of interest. Gain settings, filters, pulse repetitive frequency, sector size and depth were adjusted to optimise colour saturation. The frame rate was adjusted to greater than 100. Pulse Doppler sample volume was placed at the septal and lateral MV annulus to get the systolic velocity $\left(s^{\prime}-S\right.$ and $\left.s^{\prime}-\mathrm{L}\right)$ and the early diastolic velocity ( $e^{\prime}-\mathrm{S}$ and $\left.e^{\prime}-L\right), s^{\prime}$ was the mean value of $s^{\prime}-S$ and $s^{\prime}-L, e^{\prime}$ was the mean value of $\mathrm{e}^{\prime}-\mathrm{S}$ and $\mathrm{e}^{\prime}-\mathrm{L}$ and the ratio of $\mathrm{E} / \mathrm{e}^{\prime}$ was calculated by the following formula: $\mathrm{E} / \mathrm{e}^{\prime}=\left(\mathrm{E} / \mathrm{e}^{\prime}-\mathrm{S}+\mathrm{E} / \mathrm{e}^{\prime}-\mathrm{L}\right) / 2$. At least three consecutive beats were stored, and the images were digitised and analysed offline by EchoPac software (EchoPac 6.3.6; Vingmed-General Electric) and the average value was taken.

Normal LV geometry was defined as RWT $<0.42$ and LVMI $\leq 95 \mathrm{~g} / \mathrm{m}^{2}$ in women or LVMI $\leq 115 \mathrm{~g} / \mathrm{m}^{2}$ in men. ${ }^{6}$ The presence of LVDDF was defined as LAVI $\geq 34 \mathrm{~mL}$ / $\mathrm{m}^{2}$ and $\mathrm{e}^{\prime}-\mathrm{L} \leq 10 \mathrm{~cm} / \mathrm{s}$ or $\mathrm{e}^{\prime}-\mathrm{S} \leq 8 \mathrm{~cm} / \mathrm{s}$ according to the recommendation from the American College of Cardiology. ${ }^{17}$

\section{Statistical analysis}

Continuous normally distributed data were displayed as mean $\pm \mathrm{SD}$, and categorical data were shown as a total sample and proportion. The multivariate analysis selection criterion from the univariate analysis was $\mathrm{p}<0.05$. Multivariate logistic and linear regression analysis was performed in two models with entry and retention at a significance level of 0.05 . Model 1 was adjusted for age and gender, and model 2 was adjusted for covariates related to obesity, dyslipidaemia, diabetes, CHD, health-related behaviours and renal function (model 1+HR, BMI, physical activity, smoking and alcohol-drinking status, antihypertensive treatment, HbAlc level, serum LDL-C level, history of CHD and eGFR).

The participants were divided into two groups according to LV geometry and diastolic function. The effect of demographic data and conventional cardiovascular risk factors on LV geometry and LVDDF was analysed. The difference between the two groups was examined by independent t-test. Categorical variables were compared between the two groups by the $\mathrm{X}^{2}$ test. Multivariate logistic regression analysis was performed to investigate the independent relationship of various covariates and abnormal LV geometry and LVDDF.

To exam the effects of different ranges of SBP on LV geometry and diastolic function, all participants were divided on the basis of SBP values: group $1, \mathrm{SBP}<120 \mathrm{~mm}$ $\mathrm{Hg}$; group 2, SBP between 120 and $140 \mathrm{~mm} \mathrm{Hg}$; and group 3 , SBP $\geq 140 \mathrm{~mm} \mathrm{Hg}$. Further multivariate logistic regression analysis was performed in two models. Model 1 was adjusted for age, gender, model 2 was adjusted for age, gender, HR, BMI, physical activity, smoking and alcohol drinking status, antihypertensive treatment, HbAlc level, serum LDL-C level, history of CHD and eGFR. In these two models, group 1 was set as the reference, and the OR and $95 \%$ CI of group 2 and group 3 were calculated.

The potential linear relationship between SBP and the echocardiographic parameters was analysed by univariate linear regression analysis in the whole population, and further multivariate linear regression analysis was performed in the above two models.

SPSS V.13.0 (SPSS) was used for the calculations. A $\mathrm{p}<0.05$ was considered statistically significant.

\section{RESULTS}

A total of 1051 subjects were included in the present analysis. As shown in table 1, the mean age of the participants was $56.6 \pm 9.3$ years, and $37.9 \%$ were men. Among them, $561(53.4 \%)$ individuals had hypertension, and the mean SBP and DBP were $133.4 \pm 19.2$ and $78.5 \pm 10.7 \mathrm{~mm}$ $\mathrm{Hg}$, respectively. The number of individuals with SBP $<120 \mathrm{~mm} \mathrm{Hg}$, SBP between 12 and $140 \mathrm{~mm} \mathrm{Hg}$, and SBP $\geq 140 \mathrm{~mm} \mathrm{Hg}$ was 278 (26.4\%), $416(39.6 \%)$ and 357 (34\%), respectively. As for the echocardiographic data, the LVEDD was $47.2 \pm 4.3 \mathrm{~mm}$, LVEDV was $69.6 \pm 15.9 \mathrm{~mL}$ and LVEF was $69.0 \% \pm 6.4 \%$. LVEF was less than $50 \%$ in 
Table 1 The clinical and echocardiographic data of the study population and the comparison between the groups divided by LV geometry and LVDDF

\begin{tabular}{|c|c|c|c|c|c|c|c|}
\hline Clinical variables & $\begin{array}{l}\text { Whole } \\
\text { population } \\
(\mathrm{n}=1051)\end{array}$ & $\begin{array}{l}\text { Normal LV } \\
\text { geometry } \\
(\mathrm{n}=860)\end{array}$ & $\begin{array}{l}\text { Abnormal } \\
\text { LV geometry } \\
(\mathrm{n}=191)\end{array}$ & $P$ value & $\begin{array}{l}\text { No LVDDF } \\
(\mathrm{n}=960)\end{array}$ & $\begin{array}{l}\text { LVDDF } \\
(\mathrm{n}=91)\end{array}$ & $P$ value \\
\hline Age (years) & $56.6 \pm 9.3$ & $55.9 \pm 9.2$ & $59.8 \pm 9.1$ & $<0.01$ & $56.3 \pm 9.1$ & $60.1 \pm 10.4$ & $<0.01$ \\
\hline Gender (male, N, \%) & $398(37.9)$ & $350(40.7)$ & $48(25.1)$ & $<0.01$ & $368(38.3)$ & $30(33.0)$ & 0.31 \\
\hline HR (bpm) & $71.2 \pm 11.3$ & $70.8 \pm 11.0$ & $72.8 \pm 12.5$ & 0.03 & $71.9 \pm 11.3$ & $63.8 \pm 8.5$ & $<0.01$ \\
\hline $\mathrm{BMI}\left(\mathrm{kg} / \mathrm{m}^{2}\right)$ & $26.6 \pm 3.7$ & $26.4 \pm 3.7$ & $27.3 \pm 3.8$ & $<0.01$ & $26.5 \pm 3.8$ & $27.2 \pm 3.3$ & 0.13 \\
\hline \multicolumn{8}{|l|}{ Physical activity (N, \%) } \\
\hline Very light & $487(46.3)$ & $388(45.1)$ & 99 (51.8) & & $436(45.4)$ & $51(56.0)$ & \\
\hline Light & 108 (10.3) & 91 (10.6) & $17(8.9)$ & & $102(10.6)$ & $6(6.6)$ & \\
\hline Moderate & 215 (20.5) & $178(20.7)$ & $37(19.4)$ & & 202 (21.1) & $13(14.3)$ & \\
\hline Heavy & $166(15.8)$ & $141(16.4)$ & $25(13.1)$ & & $148(15.4)$ & $18(19.8)$ & \\
\hline Very heavy & $75(7.1)$ & $62(7.2)$ & $13(6.8)$ & 0.52 & $72(7.5)$ & $3(3.3)$ & 0.08 \\
\hline Smoking (N, \%) & $242(23.0)$ & $211(24.5)$ & $31(16.2)$ & 0.01 & $222(23.1)$ & $20(22.0)$ & 0.8 \\
\hline Current drinker (N, \%) & $253(24.1)$ & 223 (25.9) & $30(15.7)$ & $<0.01$ & $230(24.0)$ & $23(25.3)$ & 0.78 \\
\hline Hypertension (N, \%) & $561(53.4)$ & $437(50.8)$ & $124(64.9)$ & $<0.01$ & 498 (51.9) & $63(69.2)$ & $<0.01$ \\
\hline SBP (mm Hg) & $133.4 \pm 19.2$ & $132.3 \pm 19.0$ & $138.4 \pm 19.3$ & $<0.01$ & $132.8 \pm 18.9$ & $140 \pm 20.3$ & $<0.01$ \\
\hline $\mathrm{SBP}<120 \mathrm{~mm} \mathrm{Hg}$ & $278(26.4)$ & 248 (28.8) & $30(15.7)$ & & 264 (27.5) & $14(15.4)$ & \\
\hline $\begin{array}{l}\text { SBP between } 120 \text { and } 140 \mathrm{~mm} \\
\mathrm{Hg}\end{array}$ & $416(39.6)$ & 339 (39.4) & $77(40.3)$ & & $382(39.8)$ & $34(37.4)$ & \\
\hline $\mathrm{SBP} \geq 140 \mathrm{~mm} \mathrm{Hg}$ & $357(34.0)$ & 273 (31.8) & $84(44.0)$ & $<0.01$ & $314(32.7)$ & $43(47.2)$ & $<0.01$ \\
\hline DBP (mm Hg) & $78.5 \pm 10.7$ & $78.0 \pm 10.5$ & $80.3 \pm 11.0$ & $<0.01$ & $78.5 \pm 10.5$ & $78.4 \pm 11.8$ & 0.92 \\
\hline Antihypertensive treatment & 350 (33.3) & 271 (31.5) & $79(41.4)$ & $<0.01$ & $311(32.4)$ & $39(42.9)$ & 0.04 \\
\hline Diabetes mellitus (N, \%) & $193(18.4)$ & $154(17.9)$ & $39(20.4)$ & 0.42 & $174(18.1)$ & $19(20.9)$ & 0.52 \\
\hline HbA1c (\%) & $5.8 \pm 1.0$ & $5.8 \pm 1.0$ & $6.0 \pm 1.2$ & 0.11 & $5.8 \pm 1.0$ & $5.9 \pm 0.8$ & 0.71 \\
\hline LDL-C (mmol/L) & $3.0 \pm 0.8$ & $2.9 \pm 0.8$ & $3.1 \pm 0.8$ & 0.03 & $2.9 \pm 0.8$ & $3.0 \pm 0.8$ & 0.39 \\
\hline $\mathrm{CHD}(\mathrm{N}, \%)$ & $18(1.7)$ & $18(2.1)$ & $0(0)$ & 0.09 & $15(1.6)$ & $3(3.3)$ & 0.22 \\
\hline eGFR(mL/min/1.73 m²); & $92.9 \pm 14.4$ & $93.5 \pm 14.4$ & $90.5 \pm 14.1$ & 0.01 & $93.1 \pm 14.0$ & $91.1 \pm 17.4$ & 0.21 \\
\hline \multicolumn{8}{|l|}{ Echocardiographic parameters } \\
\hline LAD (mm) & $37.7 \pm 5.2$ & $36.6 \pm 5.2$ & $38.5 \pm 5.1$ & 0.03 & $37.3 \pm 5.0$ & $42.5 \pm 5.1$ & $<0.01$ \\
\hline LVEDD (mm) & $47.2 \pm 4.3$ & $47.3 \pm 4.0$ & $46.4 \pm 5.6$ & 0.04 & $46.9 \pm 4.2$ & $49.8 \pm 4.6$ & $<0.01$ \\
\hline LVEDV (mL) & $69.6 \pm 15.9$ & $69.5 \pm 15.8$ & $69.8 \pm 16.2$ & 0.84 & $69.2 \pm 15.4$ & $73.5 \pm 20.1$ & 0.01 \\
\hline LVESV (mL) & $21.9 \pm 8.7$ & $21.8 \pm 8.7$ & $22.0 \pm 8.7$ & 0.81 & $21.7 \pm 8.1$ & $24.1 \pm 13.7$ & 0.1 \\
\hline LVEF (\%) & $69.0 \pm 6.4$ & $69.0 \pm 6.2$ & $68.9 \pm 7.1$ & 0.88 & $69.1 \pm 6.3$ & $68.3 \pm 7.1$ & 0.31 \\
\hline \multicolumn{8}{|l|}{ LVMI $\left(\mathrm{g} / \mathrm{m}^{2}\right)$} \\
\hline Male $(n=398)$ & $77.9 \pm 17.9$ & $76.1 \pm 15.9$ & $90.9 \pm 25.3$ & $<0.01$ & $76.8 \pm 17.5$ & $91.2 \pm 18.5$ & $<0.01$ \\
\hline Female $(n=653)$ & $74.3 \pm 17.1$ & $69.1 \pm 12.3$ & $93.2 \pm 18.8$ & $<0.01$ & $72.8 \pm 16.2$ & $89.2 \pm 18.9$ & $<0.01$ \\
\hline IVST (mm) & $8.3 \pm 1.2$ & $7.9 \pm 1.0$ & $9.7 \pm 1.0$ & $<0.01$ & $8.2 \pm 1.1$ & $8.7 \pm 1.1$ & $<0.01$ \\
\hline LVPWT (mm) & $8.2 \pm 1.1$ & $7.9 \pm 1.0$ & $9.6 \pm 0.8$ & $<0.01$ & $8.2 \pm 1.1$ & $8.6 \pm 1.1$ & $<0.01$ \\
\hline RWT (\%) & $35.1 \pm 5.7$ & $33.6 \pm 4.4$ & $42.0 \pm 5.6$ & $<0.01$ & $35.1 \pm 5.7$ & $34.9 \pm 5.0$ & 0.69 \\
\hline LAVI $\left(\mathrm{mL} / \mathrm{m}^{2}\right)$ & $25.0 \pm 6,9$ & $24.7 \pm 6.7$ & $26.5 \pm 7.8$ & $<0.01$ & $23.7 \pm 5.3$ & $39.4 \pm 5.5$ & $<0.01$ \\
\hline $\mathrm{E}(\mathrm{cm} / \mathrm{s})$ & $69.2 \pm 17.6$ & $69.5 \pm 17.7$ & $67.8 \pm 17.2$ & 0.25 & $68.3 \pm 16.8$ & $78.6 \pm 22.7$ & $<0.01$ \\
\hline $\mathrm{A}(\mathrm{cm} / \mathrm{s})$ & $79.2 \pm 19.4$ & $77.8 \pm 19.1$ & $85.5 \pm 20.0$ & $<0.01$ & $78.7 \pm 18.7$ & $85.0 \pm 25.8$ & 0.02 \\
\hline $\mathrm{E} / \mathrm{A}$ & $0.92 \pm 0.31$ & $0.93 \pm 0.31$ & $0.83 \pm 0.26$ & $<0.01$ & $0.91 \pm 0.30$ & $0.98 \pm 0.36$ & 0.02 \\
\hline $\mathrm{s}^{\prime}-\mathrm{S}(\mathrm{cm} / \mathrm{s})$ & $7.5 \pm 1.4$ & $7.5 \pm 1.4$ & $7.3 \pm 1.6$ & 0.11 & $7.5 \pm 1.4$ & $6.7 \pm 1.2$ & $<0.01$ \\
\hline $\mathrm{s}^{\prime}-\mathrm{L}(\mathrm{cm} / \mathrm{s})$ & $8.8 \pm 2.1$ & $8.8 \pm 2.1$ & $8.8 \pm 2.2$ & 0.88 & $8.9 \pm 2.1$ & $7.8 \pm 1.7$ & $<0.01$ \\
\hline
\end{tabular}


Table 1 Continued

\begin{tabular}{|c|c|c|c|c|c|c|c|}
\hline Clinical variables & $\begin{array}{l}\text { Whole } \\
\text { population } \\
(n=1051)\end{array}$ & $\begin{array}{l}\text { Normal LV } \\
\text { geometry } \\
(\mathrm{n}=860)\end{array}$ & $\begin{array}{l}\text { Abnormal } \\
\text { LV geometry } \\
(n=191)\end{array}$ & $P$ value & $\begin{array}{l}\text { No LVDDF } \\
(n=960)\end{array}$ & $\begin{array}{l}\text { LVDDF } \\
(n=91)\end{array}$ & $P$ value \\
\hline $\mathrm{e}^{\prime}-\mathrm{S}(\mathrm{cm} / \mathrm{s})$ & $6.9 \pm 1.9$ & $7.1 \pm 1.9$ & $6.2 \pm 1.8$ & $<0.01$ & $7.0 \pm 1.9$ & $6.2 \pm 1.5$ & $<0.01$ \\
\hline$e^{\prime}-L(c m / s)$ & $9.8 \pm 2.7$ & $10.0 \pm 2.7$ & $8.8 \pm 2.5$ & $<0.01$ & $9.9 \pm 2.7$ & $8.7 \pm 2.3$ & $<0.01$ \\
\hline
\end{tabular}

A, peak velocity of late diastolic transmitral flow; BMI, body mass index; $\mathrm{CHD}$, coronary heart disease; DBP, diastolic blood pressure; $\mathrm{E}$, peak velocity of early diastolic transmitral flow; $e^{\prime}$, the mean value of $e^{\prime}-S$ and $e^{\prime}-L ; E / A$, the ratio of $E$ and $A ; E / e^{\prime}$, the mean value of E/e'-S and E/e'-L; eGFR, estimated glomerular filtration rate; $e^{\prime}-L$, the early diastolic velocity of the lateral mitral annulus; $e^{\prime}-S$, the early diastolic velocity of the septal mitral annulus; HbA1C, glycated haemoglobin A1c; HR, heart rate; IVST, interventricular septal wall thickness; LAD, left atrial anteroposterior dimension; LAVI, left atrial volume index; LDL-C, low-density lipoprotein cholesterol; LV, left ventricular; LVDDF, left ventricular diastolic dysfunction; LVEDD, left ventricular end-diastolic dimension; LVEDV, left ventricular end-diastolic volume; LVEF, left ventricular ejection fraction; LVESV, left ventricular end-systolic volume; LVMI, left ventricular mass index; LVPWT, left ventricular posterior wall thickness; RWT, relative wall thickness; $s^{\prime}$, the mean value of $s^{\prime}-L$ and $s^{\prime}-S$; SBP, systolic blood pressure; $s^{\prime}-L$, the systolic peak velocity of the lateral mitral annulus; $s^{\prime}-S$, the systolic peak velocity of the septal mitral annulus.

11 individuals, five of whom had old myocardial infarction. The LVMI of male and female participants was $77.9 \pm 17.9 \mathrm{~g} / \mathrm{m}^{2}$ and $74.3 \pm 17.1 \mathrm{~g} / \mathrm{m}^{2}$, respectively, and RWT was $35.1 \% \pm 5.7 \%$. The parameters of $\mathrm{LV}$ diastolic function were as follows: LAVI was $25.0 \pm 6.9 \mathrm{~mL} / \mathrm{m}^{2}, \mathrm{E}$ was $69.2 \pm 17.6 \mathrm{~cm} / \mathrm{s}$ and $\mathrm{E} / \mathrm{A}$ ratio was $0.92 \pm 0.31$. $\mathrm{e}^{\prime}-\mathrm{S}$ and $\mathrm{e}^{\prime}-\mathrm{L}$ were $6.9 \pm 1.9 \mathrm{~cm} / \mathrm{s}$ and $9.8 \pm 2.7 \mathrm{~cm} / \mathrm{s}$, respectively, and the number of individuals with abnormal LV geometry and LVDDF was $191(18.2 \%)$ and $91(8.7 \%)$, respectively. Other clinical and echocardiographic characteristics are displayed in table 1.

\section{Association of SBP with LVDDF and abnormal LV geometry}

As shown in table 1, participants with abnormal LV geometry and diastolic function were older ( $59.8 \pm 9.1$ vs $55.9 \pm 9.2$ years, and $60.1 \pm 10.4$ vs $56.3 \pm 9.1$ years, respectively, all $\mathrm{p}<0.01)$, had higher prevalence of hypertension and higher SBP $(64.9 \%$ vs $50.8 \%$ and $138.4 \pm 19.3$ vs $132.3 \pm 19.0 \mathrm{~mm}$ $\mathrm{Hg}, 69.2 \%$ vs $51.9 \%$ and $140.0 \pm 20.3$ vs $132.8 \pm 18.9 \mathrm{~mm} \mathrm{Hg}$, respectively, all $\mathrm{p}<0.01$ ), larger proportion of participants with higher SBP group and antihypertensive treatment (all $\mathrm{p}<0.05$ ). The participants with abnormal LV geometry had higher BMI $\left(27.3 \pm 3.8\right.$ vs $\left.26.4 \pm 3.7 \mathrm{~kg} / \mathrm{m}^{2}, \mathrm{p}<0.01\right)$, higher LDL-C $(3.1 \pm 0.8$ vs $2.9 \pm 0.8 \mathrm{mmol} / \mathrm{L}, \mathrm{p}<0.01)$, lower eGFR $\left(90.5 \pm 14.1\right.$ vs $\left.93.5 \pm 14.4 \mathrm{~mL} / \mathrm{min} / 1.73 \mathrm{~m}^{2}, \mathrm{p}<0.01\right)$, less likely to be male $(25.1 \%$ vs $40.7 \%, \mathrm{p}<0.01)$ and less likely to be a current smoker and alcohol drinker $(16.2 \%$ vs $24.5 \%$ and $15.7 \%$ vs $25.9 \%$, respectively, all $\mathrm{p}<0.01)$. Other data were shown in table 1.

In the multivariate analysis (table 2), SBP was independently related to abnormal LV geometry and LVDDF (OR $1.01,95 \%$ CI 1.00 to 1.02 , and OR $1.02,95 \%$ CI 1.01 to 1.03 , respectively, all $\mathrm{p}<0.05$ ). Other conventional risk factors independently related to abnormal LV geometry and LVDDF are shown in table 2.
The effects of different ranges of SBP on LV geometry and diastolic function

The effects of different ranges of SBP on LV geometry and diastolic function were analysed in two models (figure 2).

Table 2 The multivariate analysis of the relationship between the risk factors and abnormal LV geometry and LVDDF

\begin{tabular}{llll}
\hline & OR & 95\% Cl & P value \\
\hline $\begin{array}{l}\text { Abnormal LV geometry } \\
\text { Age }(+1 \text { year) }\end{array}$ & 1.05 & 1.03 to 1.08 & $<0.01$ \\
\hline Male & 0.46 & 0.26 to 0.79 & $<0.01$ \\
\hline HR $(+1 \mathrm{bpm})$ & 1.01 & 1.00 to 1.03 & 0.10 \\
\hline BMI $\left(+1 \mathrm{~kg} / \mathrm{m}^{2}\right)$ & 1.06 & 1.01 to 1.11 & 0.02 \\
\hline Smoking & 1.27 & 0.71 to 2.28 & 0.42 \\
\hline $\begin{array}{l}\text { Current drinker } \\
\text { SBP }(+1 \mathrm{~mm} \mathrm{Hg})\end{array}$ & 0.78 & 0.45 to 1.35 & 0.38 \\
$\begin{array}{l}\text { Antihypertensive } \\
\text { Treatment }\end{array}$ & 0.92 & 0.64 to 1.34 & 0.68 \\
\hline $\begin{array}{l}\text { LDL }(+1 \mathrm{mmol} / \mathrm{L}) \\
\text { eGFR }(+1 \mathrm{~mL} /\end{array}$ & 1.01 & 0.82 to 1.25 & 0.94 \\
min $\left./ 1.73 \mathrm{~m}^{2}\right)$ & 1.0 & 0.99 to 1.02 & 0.54 \\
\hline LVDF & & & \\
\hline
\end{tabular}

LVDDF

\begin{tabular}{|lllr|}
\hline Age $(+1$ year $)$ & 1.03 & 1.00 to 1.05 & 0.04 \\
\hline $\mathrm{HR}(+1 \mathrm{bpm})$ & 0.92 & 0.90 to 0.94 & $<0.01$ \\
\hline $\mathrm{SBP}(+1 \mathrm{~mm} \mathrm{Hg})$ & 1.02 & 1.01 to 1.03 & $<0.01$ \\
$\begin{array}{l}\text { Antihypertensive } \\
\text { treatment }\end{array}$ & 1.05 & 0.64 to 1.72 & 0.85 \\
\hline
\end{tabular}

BMI, body mass index; HR, heart rate; LDL, low-density lipoprotein; LV, left ventricular; LVDDF, left ventricular diastolic dysfunction; SBP, systolic blood pressure; eGFR, estimated glomerular filtration rate. 


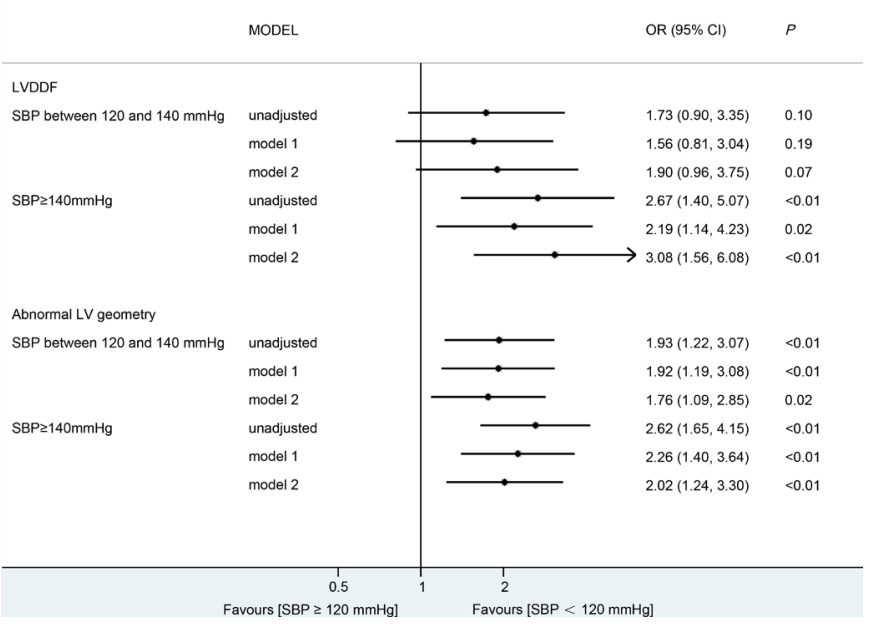

Figure 2 The effects of different ranges of SBP on LV geometry and diastolic function, SBP $<120 \mathrm{~mm} \mathrm{Hg}$ was set as reference. Model 1 was adjusted for age, gender, model 2 was adjusted for age, gender, HR, BMI, physical activity, smoking and alcohol drinking status, antihypertensive treatment, $\mathrm{HbA} 1 \mathrm{c}$ level, serum LDL-C level, history of CHD and eGFR. $\mathrm{BMI}$, body mass index; CHD, coronary heart disease; eGFR, estimated glomerular filtration rate; $\mathrm{HbA1c}$, haemoglobin $\mathrm{A} 1 \mathrm{c}$; $H R$, heart rate; LDL-C, low-density lipoprotein cholesterol; LV, left ventricular; LVDDF, left ventricular diastolic dysfunction; SBP, systolic blood pressure.

In the first model, the participants in group 3 had a higher risk odds of abnormal LVDDF and LV geometry than those in group 1 (OR 2.19, 95\% CI 1.14 to 4.23 for LVDDF and OR 2.26, 95\% CI 1.40 to 3.64 for abnormal LV geometry, all $\mathrm{p}<0.05)$. These differences remained statistically significant in the second model (OR 3.08, 95\% CI 1.56 to 6.08 for LVDDF and OR 2.02, 95\% CI 1.24 to 3.30 for abnormal LV geometry, all $\mathrm{p}<0.05$ ).

Compared with the individuals of group 1, participants of group 2 also showed increased risk odds of abnormal LV geometry in both models (OR 1.92, 95\% CI 1.19 to 3.08 in model 1 and OR 1.76 , 95\% CI 1.09 to 2.85 in model 2, all $\mathrm{p}<0.05$ ) (figure 2 ). The participants of group 2 had greater LVMI than those of group 1 but lower than those from group 3 (table 3 ).

Although compared with the individuals of group 1, participants of group 2 did not show increased risk odds of LVDDF in both models (figure 2), the parameters of LV diastolic function ( $\mathrm{e}^{\prime}$ and $\mathrm{E} / \mathrm{e}^{\prime}$ ) were progressively worse in group 2 and group 3 in comparison with group 1 (table 3 ).

\section{Linear association of SBP with cardiac remodeling and} diastolic function assessed by echocardiography in the whole population

In the univariate analysis, SBP was positively correlated with LVMI, LVEDD, RWT, LAVI and E/ $\mathrm{e}^{\prime}$ (all $\mathrm{p}<0.01$ ) and was negatively correlated with $\mathrm{e}^{\prime}(\mathrm{p}<0.01)$. In both models, after adjusting for the relevant parameters, SBP was still independently correlated with the echocardiographic parameters about cardiac remodelling (LVMI and LVEDD, $\mathrm{p}<0.01$ ) and LV diastolic function (LAVI, $\mathrm{e}^{\prime}$, and $\mathrm{E} / \mathrm{e}^{\prime}$, all $\mathrm{p}<0.01$ ) (table 4 ).

We randomly selected 10 individuals for measurement of echocardiographic data by two experienced physicians, one of whom took the measurement again 1 day later and calculated the intraobserver and interobserver variability

Table 3 The effects of different range of SBP on LV geometry and diastolic function

\begin{tabular}{lll}
$\begin{array}{l}\text { SBP between } 120 \text { and } 140 \mathrm{~mm} \mathrm{Hg} \\
\text { vs SBP }<120 \mathrm{~mm} \mathrm{Hg}\end{array}$ & $\begin{array}{l}\text { SBP } \geq 140 \mathrm{~mm} \mathrm{Hg} \text { vs SBP } \\
\text { between } 120 \text { and } 140 \mathrm{~mm} \mathrm{Hg}\end{array}$ & $\begin{array}{l}\text { SBP } \geq 140 \mathrm{~mm} \mathrm{Hg} \text { vs SBP } \\
<120 \mathrm{~mm} \mathrm{Hg}\end{array}$ \\
\cline { 1 - 2 } & &
\end{tabular}

$\begin{array}{lllllllllll}B(S E) & \beta & P \text { value } & & B(S E) & \beta & & P \text { value } & B(S E) & \beta & P \text { value }\end{array}$

\begin{tabular}{llllllllll}
\hline Model 1 & & & & & & & & \\
LVMI $\left(\mathrm{g} / \mathrm{m}^{2}\right)$ & $3.86(1.33)$ & 0.11 & $<0.01$ & $2.69(1.24)$ & 0.08 & 0.03 & $6.55(1.40)$ & 0.18 & $<0.01$ \\
LVEDD $(\mathrm{mm})$ & $0.92(0.33)$ & 0.1 & $<0.01$ & $0.48(0.30)$ & 0.05 & 0.11 & $1.41(0.34)$ & 0.15 & $<0.01$ \\
RWT $(\%)$ & $0.32(0.44)$ & 0.03 & 0.47 & $0.44(0.41)$ & 0.04 & 0.26 & $0.75(0.46)$ & 0.06 & 0.11 \\
LAVI & $1.25(0.53)$ & 0.09 & 0.02 & $0.33(0.49)$ & 0.02 & 0.54 & $1.58(0.55)$ & 0.11 & $<0.01$ \\
$\mathrm{e}^{\prime}$ & $-0.47(0.14)$ & -0.11 & $<0.01$ & $-0.44(0.13)$ & -0.1 & $<0.01$ & $-0.90(0.15)$ & -0.21 & $<0.01$
\end{tabular}

\section{Model 2}

$\begin{array}{llllllllll}\text { LVMI }\left(\mathrm{g} / \mathrm{m}^{2}\right) & 3.78(1.36) & 0.11 & <0.01 & 2.77(1.22) & 0.08 & 0.02 & 6.55(1.45) & 0.18 & <0.01 \\ \text { LVEDD }(\mathrm{mm}) & 0.66(0.32) & 0.07 & 0.03 & 0.46(0.28) & 0.05 & 0.11 & 1.12(0.33) & 0.12 & <0.01 \\ \text { RWT }(\%) & 0.12(0.45) & 0.01 & 0.79 & 0.25(0.41) & 0.02 & 0.5 & 0.37(0.47) & 0.03 & 0.43 \\ \text { LAVI } & 1.39(0.51) & 0.1 & <0.01 & 0.41(0.46) & 0.03 & 0.44 & 1.80(0.54) & 0.13 & <0.01 \\ e^{\prime} & -0.27(0.14) & -0.06 & 0.04 & -0.32(0.13) & -0.08 & 0.01 & -0.60(0.15) & -0.14 & <0.01\end{array}$

$\beta$, standardised correlation coefficients; B, non-standardised correlation coefficients; $e^{\prime}$, the mean value of $e^{\prime}-S$ and $e^{\prime}-L ; E / e^{\prime}$, the mean value of E/e'-S and E/e'-L; LAVI, Left Atrial Volume Index; LV, left ventricular; LVDDF, left ventricular diastolic dysfunction; LVEDD, left ventricular end-diastolic dimension; LVMI, Left Ventricular Mass Index; RWT, relative wall thickness; SBP, systolic blood pressure. 
Table 4 Associations of SBP with cardiac remodelling and diastolic function assessed by echocardiography in the whole population

\begin{tabular}{|c|c|c|c|c|c|c|}
\hline & \multicolumn{2}{|c|}{ Unadjusted } & \multicolumn{2}{|c|}{ Model 1} & \multicolumn{2}{|c|}{ Model 2} \\
\hline & B & P value & B & $P$ value & B & $P$ value \\
\hline LVMI $\left(\mathrm{g} / \mathrm{m}^{2}\right)$ & 0.2 & $<0.01$ & 0.2 & $<0.01$ & 0.2 & $<0.01$ \\
\hline $\begin{array}{l}\text { LVEDD } \\
(\mathrm{mm})\end{array}$ & 0.04 & $<0.01$ & 0.03 & $<0.01$ & 0.03 & $<0.01$ \\
\hline RWT (\%) & 0.02 & $<0.01$ & 0.02 & 0.10 & 0.01 & 0.49 \\
\hline $\begin{array}{l}\text { LAVI (mL/ } \\
\left.\mathrm{m}^{2}\right)\end{array}$ & 0.05 & $<0.01$ & 0.04 & $<0.01$ & 0.04 & $<0.01$ \\
\hline$e^{\prime}$ & -0.03 & $<0.01$ & -0.02 & $<0.01$ & -0.01 & $<0.01$ \\
\hline$E / e^{\prime}$ & 0.03 & $<0.01$ & 0.03 & $<0.01$ & 0.02 & $<0.01$ \\
\hline
\end{tabular}

Model 1: adjusted by age, gender.

Model 2: adjusted by age, gender, heart rate, bbody mass index, physical activity, smoking and alcohol drinking status, SBP, antihypertensive treatment, blood glucose level, serum low-density lipoprotein cholesterol level, history of coronary artery disease and estimated glomerular filtration rate.

$B$, non-standardised correlation coefficients; $e^{\prime}$, the mean value of $e^{\prime}-S$ and $e^{\prime}-L ; E / e^{\prime}$, the mean value of $E / e^{\prime}-S$ and $E / e^{\prime}-L ; L A V I$, Left atrial Volume Index; LVEDD, left ventricular end-diastolic dimension; LVMI, Left Ventricular Mass Index; RWT, relative wall thickness; SBP, systolic blood pressure.

which were less than $4 \%$ and $5 \%$ in our echocardiographic laboratory.

\section{DISCUSSION}

In this cross-sectional population-based study of general Chinese population, we assessed the relationship between the LV diastolic functional and structural changes and SBP, and we have two major findings.

First, SBP was independently related to the abnormal LV geometry and had an independent linear relationship with LVMI. Compared with individuals with SBP $<120 \mathrm{~mm} \mathrm{Hg}$, participants with SBP between 120 and $140 \mathrm{~mm} \mathrm{Hg}$ had higher LVMI, although this LV remodelling was less severe than what was seen in participants with $\mathrm{SBP} \geq 140 \mathrm{~mm} \mathrm{Hg}$. LV remodelling is a well-known marker of cardiovascular risk, ${ }^{18}$ and $\mathrm{BP}$ is one of the major determinants of changes in $\mathrm{LV}$ geometry. As shown in this study, every $1 \mathrm{~mm} \mathrm{Hg}$ increase in SBP related to $1 \%$ increase in the odds of abnormal LV geometry. In previous studies, ${ }^{9} 19$ prehypertensive patients were found to have higher LVM compared with normotensive subjects, which was consistent with our study. In our study, LV remodelling was based only on increasing LVMI, with no difference in RWT among different ranges of SBP and no difference in LVEDD between the individuals with SBP between 120 and $140 \mathrm{~mm} \mathrm{Hg}$ and those with SBP $\geq 140 \mathrm{~mm} \mathrm{Hg}$. This finding was not consistent with previous research. ${ }^{9}$ The reason was unclear, but the participants in our study were older than those in the previous research (56.6 \pm 9.3 vs $40.3 \pm 8.1$ years), and different age and sample size might be the possible explanation for the different results.
The second major finding was the effect of elevated SBP on subclinical LV diastolic function. Many previous studies $^{8} 92021$ suggested prehypertension was related to and accelerated the development of diastolic dysfunction of the heart. Our study showed that such association was continuous as the SBP increased. In our whole-study population, for every $1 \mathrm{~mm} \mathrm{Hg}$ increase in SBP, the risk of diastolic dysfunction increased by $2 \%$ after adjusting for conventional cardiac risk factors. Further quantitative analysis of diastolic function (expressed as $\mathrm{e}^{\prime}, \mathrm{E} / \mathrm{e}^{\prime}$ ) indicated that a dose-response relationship between SBP and LV diastolic parameters existed across the study population, from the lowest SBP to the highest SBP. Compared with individuals who had $\mathrm{SBP}<120 \mathrm{~mm} \mathrm{Hg}$, participants with SBP between 120 and $140 \mathrm{~mm} \mathrm{Hg}$ had higher E/e' and lower $\mathrm{e}^{\prime}$, although the impairment of LV diastolic function was less severe than what was seen in participants with SBP $\geq 140 \mathrm{~mm} \mathrm{Hg}$.

In a previous study, ${ }^{19}$ Santos $e t$ al found more frequent LVDDF in prehypertension than optimal BP. In the present study, there was no statistically significant difference in the prevalence of the diastolic dysfunction between the participants with SBP between 120 and $140 \mathrm{~mm} \mathrm{Hg}$ and those with $\mathrm{SBP}<120 \mathrm{~mm} \mathrm{Hg}$. The reason was unclear, but the different definition of LVDDF might be the reason, and Santos et al used a more complex definition.

LV remodelling and LVDDF were the most critical factors in the pathogenesis of many cardiac diseases, such as heart failure with normal ejection fraction, and they started before the onset of symptoms. The newest guideline ${ }^{22}$ classified $\mathrm{BP}$ in adults into three categories: normal BP (SBP $<120 \mathrm{~mm} \mathrm{Hg}$ and DBP $<80 \mathrm{~mm} \mathrm{Hg}$ ), elevated BP (SBP between 120 and $130 \mathrm{~mm} \mathrm{Hg}$ and DBP $<80 \mathrm{~mm} \mathrm{Hg}$ ), and hypertension ( $\mathrm{SBP} \geq 130 \mathrm{~mm} \mathrm{Hg}$ or DBP $\geq 80 \mathrm{~mm} \mathrm{Hg}$ ). Our findings seemed to support this new classification. When the SBP exceeded the normal range $(120 \mathrm{~mm} \mathrm{Hg}), \mathrm{LV}$ geometry ((LVMI) and LV diastolic function (expressed as $\mathrm{e}^{\prime}, \mathrm{E} / \mathrm{e}^{\prime}$ ) were linearly, negatively correlated with SBP. From this perspective, more intensive BP control, especially controlling the SBP below $120 \mathrm{~mm} \mathrm{Hg}$, might reduce the impairment of $\mathrm{LV}$ structure and diastolic function. It also reminded us that in the population, elevated SBP alone was associated with impairment of LV structure and diastolic function, more attention should be paid to the control of SBP. Our findings were consistent with recent systolic blood pressure intervention trial (SPRINT) study. ${ }^{23}$

The strengths of the study include its large sample from the general Chinese population and its standardised acquisition of basic characteristics and echocardiography examinations. There are several limitations of this study: one limitation is that this is a cross-sectional study and cannot prove a causal relationship between the geometric/functional changes and SBP; another limitation is that this study was conducted in a Chinese population; studies that involve other ethnic populations are needed to replicate our results; third limitation is that we included self-reported hypertension into the definition of hypertension, a possibility of 
manipulating the BP readings exists, so end-digit preference for zero numbers and specific-value preference for readings just below the alert threshold exists. ${ }^{24}$

\section{CONCLUSION}

In the present population-based study, we found that in the Chinese population aged 35 years or older, SBP was independently related to abnormal LV geometry and LVDDF, SBP between 120 and $140 \mathrm{~mm} \mathrm{Hg}$ was independently related to worse LV remodelling and diastolic function. Our findings indicate the potential benefit of intensive SBP control. But what is the threshold for SBP control, and whether the benefits of intensive SBP control on the heart will lead to improved long-term outcomes, all these issues warrant further investigation.

\section{Author affiliations \\ ${ }^{1}$ Cardiology, Peking Union Medical College Hospital, Dongcheng-qu, Beijing, China ${ }^{2}$ Neurology, Peking Union Medical College Hospital, Dongcheng-qu, Beijing, China ${ }^{3}$ Central Research Laboratory, Peking Union Medical College Hospital, Dongcheng- qu, Beijing, China \\ ${ }^{4}$ Radiology, Peking Union Medical College Hospital, Dongcheng-qu, Beijing, China}

Contributors LY, ZYi, CL, JZ and SZ designed the study. LY, LJ, ZL, ZF, TZ, ZYa, CW, $\mathrm{BH}$ and $\mathrm{WH}$ collected the data. $\mathrm{LY}$ and $\mathrm{ZD}$ analysed the data. All authors participated actively in the writing of the manuscript and approved the final draft.

Funding This work was supported by the Fundamental Research Funds for the Central Universities, CAMS Innovation Fund for Medical Sciences (CIFMS) (no.2017-12M-3-008, 2016-I2M-4-003 and no. 2016-12M-3-011), Peking Union Medical College (PUMC) Youth Fund, the National Natural Science Foundation of China (81500306) and the National Key Research and Development Program of China (grant no. 2016YFC0901500 and 2016YFC0901502).

Competing interests None declared.

Patient consent for publication Not required.

Ethics approval Ethics approval to conduct the study was obtained from by the Institutional Review Board of the Institute of Basic Medical Sciences, Chinese Academy of Medical Sciences (approval No. 009-2014, 031-2017).

Provenance and peer review Not commissioned; externally peer reviewed.

Data availability statement All data relevant to the study are included in the article or uploaded as online supplementary information.

Open access This is an open access article distributed in accordance with the Creative Commons Attribution Non Commercial (CC BY-NC 4.0) license, which permits others to distribute, remix, adapt, build upon this work non-commercially, and license their derivative works on different terms, provided the original work is properly cited, appropriate credit is given, any changes made indicated, and the use is non-commercial. See: http://creativecommons.org/licenses/by-nc/4.0/.

\section{REFERENCES}

1. Lewington S, Clarke R, Qizilbash N, et al. Age-Specific relevance of usual blood pressure to vascular mortality: a meta-analysis of individual data for one million adults in 61 prospective studies. Lancet 2002;360:1903-13.

2. Lawes CMM, Rodgers A, Bennett DA, et al. Blood pressure and cardiovascular disease in the Asia Pacific region. J Hypertens 2003;21:707-16.

3. Mancia G, De Backer G, Dominiczak A, et al. 2007 guidelines for the management of arterial hypertension: the task force for the management of arterial hypertension of the European Society of hypertension (ESH) and of the European Society of cardiology (ESC). Eur Heart J 2007;28:1462-536.

4. Sahle BW, Owen AJ, Krum H, et al. Incidence of heart failure in 6083 elderly hypertensive patients: the second Australian National blood pressure study (ANBP2). Eur J Heart Fail 2016;18:38-45.

5. Williams B, Mancia G, Spiering W, et al. 2018 ESC/ESH guidelines for the management of arterial hypertension: the task force for the management of arterial hypertension of the European Society of cardiology and the European Society of hypertension: the task force for the management of arterial hypertension of the European Society of cardiology and the European Society of hypertension. J Hypertens 2018;36:1953-2041.

6. Marwick TH, Gillebert TC, Aurigemma G, et al. Recommendations on the use of echocardiography in adult hypertension: a report from the European association of cardiovascular imaging (EACVI) and the American Society of echocardiography (ASE). J Am Soc Echocardiogr 2015;28:727-54.

7. Leite-Moreira AF. Current perspectives in diastolic dysfunction and diastolic heart failure. Heart 2006;92:712-8.

8. Markus MRP, Stritzke J, Lieb W, et al. Implications of persistent prehypertension for ageing-related changes in left ventricular geometry and function: the MONICA/KORA Augsburg study. $J$ Hypertens 2008;26:2040-9.

9. Jung JY, Park SK, Oh C-M, et al. The influence of prehypertension, controlled and uncontrolled hypertension on left ventricular diastolic function and structure in the general Korean population. Hypertens Res 2017;40:606-12.

10. Chobanian AV, Bakris GL, Black HR, et al. The seventh report of the joint National Committee on prevention, detection, evaluation, and treatment of high blood pressure: the JNC 7 report. JAMA 2003;289:2560-72.

11. Vishram JKK, Borglykke A, Andreasen AH, et al. Impact of age on the importance of systolic and diastolic blood pressures for stroke risk: the MONICA, risk, genetics, archiving, and monograph (MORGAM) project. Hypertension 2012;60:1117-23.

12. Franklin SS, Gustin W, Wong ND, et al. Hemodynamic patterns of age-related changes in blood pressure. The Framingham heart study. Circulation 1997;96:308-15.

13. Hua Q, Fan L, Li J, et al. 2019 Chinese guideline for the management of hypertension in the elderly. J Geriatr Cardiol 2019;16:67-99.

14. Lang RM, Badano LP, Mor-Avi V, et al. Recommendations for cardiac chamber quantification by echocardiography in adults: an update from the American Society of echocardiography and the European association of cardiovascular imaging. J Am Soc Echocardiogr 2015;28:e14:1-39.

15. Nagueh SF, Smiseth OA, Appleton CP, et al. Recommendations for the Evaluation of Left Ventricular Diastolic Function by Echocardiography: An Update from the American Society of Echocardiography and the European Association of Cardiovascular Imaging. J Am Soc Echocardiogr 2016;29:277-314.

16. Pai RG, Gill KS, Amplitudes Gill KS:. Amplitudes, durations, and timings of apically directed left ventricular myocardial velocities: II. systolic and diastolic asynchrony in patients with left ventricular hypertrophy. J Am Soc Echocardiogr 1998;11:112-8.

17. Flachskampf FA, Biering-Sørensen T, Solomon SD, et al. Cardiac Imaging to Evaluate Left Ventricular Diastolic Function. JACC Cardiovasc Imaging 2015;8:1071-93.

18. Gardin JM, McClelland R, Kitzman D, et al. M-mode echocardiographic predictors of six- to seven-year incidence of coronary heart disease, stroke, congestive heart failure, and mortality in an elderly cohort (the cardiovascular health study). Am J Cardiol 2001;87:1051-7.

19. Santos ABS, Gupta DK, Bello NA, et al. Prehypertension is associated with abnormalities of cardiac structure and function in the Atherosclerosis risk in Communities study. Am J Hypertens 2016;29:568-74.

20. Jung JY, Park SK, Ryoo J-H, et al. The optimal cut-off of blood pressure related to left ventricular diastolic dysfunction and remodeling in Asian diabetic patients. J Cardiol 2018;71:16-23.

21. Yașar E, Tașolar H, Açikgöz N. Left ventricular myocardial performance index in prehypertensive patients with normal coronary arteries. Blood Press Monit 2017;22:149-53.

22. Whelton PK, Carey RM, Aronow WS, et al. 2017 ACC/AHA/AAPA/ ABC/ACPM/AGS/APhA/ASH/ASPC/NMA/PCNA guideline for the prevention, detection, evaluation, and management of high blood pressure in adults: a report of the American College of Cardiology/ American heart association Task force on clinical practice guidelines. J Am Coll Cardiol 2018;71:e127-248.

23. Soliman EZ, Ambrosius WT, Cushman WC, et al. Effect of intensive blood pressure lowering on left ventricular hypertrophy in patients with hypertension: sprint (systolic blood pressure intervention trial). Circulation 2017;136:440-50.

24. Parker RA, Paterson M, Padfield P, et al. Are self-reported telemonitored blood pressure readings affected by end-digit preference: a prospective cohort study in Scotland. BMJ Open 2018;8:e019431. 